Bull. Chem. Soc. Ethiop. 2012, 26(1), 73-84.

ISSN 1011-3924

Printed in Ethiopia

DOI: http://dx.doi.org/10.4314/bcse.v26i1.8

(c) 2012 Chemical Society of Ethiopia

\title{
DIFFERENTIAL PULSE VOLTAMMETRIC DETERMINATION OF THEOPHYLLINE AT POLY(4-AMINO-3-HYDROXYNAPHTHALENE SULFONIC ACID) MODIFIED GLASSY CARBON ELECTRODE
}

\author{
Meareg Amare and Shimelis Admassie ${ }^{*}$ \\ Department of Chemistry, Addis Ababa University, P.O. Box 1176, Addis Ababa, Ethiopia
}

(Received June 1, 2011; revised September 13, 2011)

\begin{abstract}
A glassy carbon electrode (GCE) was modified with electropolymerized film of 4-amino-3hydroxynaphthalene sulfonic acid (AHNSA) in $0.1 \mathrm{M} \mathrm{HNO}_{3}$. Cyclic voltammetry (CV) was used to study the electrochemical properties of the polymer film. The polymer film-modified electrode was used to electrochemically detect theophylline (TP) in drug samples. The polymer-modified electrode showed excellent electrocatalytic activity for the oxidation of TP. Under optimal experimental conditions, there was a good linear relationship between anodic peak current and TP concentration in the range from $1.0 \times 10^{-6}$ to $1.0 \times 10^{-4} \mathrm{M}$ with the correlation coefficient of 0.9983 and a detection limit of $4.7 \times 10^{-8} \mathrm{M}(\mathrm{S} / \mathrm{N}=3$ for $\mathrm{n}=6)$. The application of the polymer-modified GCE for the determination of TP in drug formulations showed good recovery and reproducible results.
\end{abstract}

KEY WORDS: Cyclic voltammetry, Differential pulse voltammetry, Theophylline, 4-Amino-3hydroxynaphthalene sulfonic acid

\section{INTRODUCTION}

The N-methyl derivatives of xanthine (Table 1), including theophylline (3,7-dihydro-1,3dimethyl-1H-purine- 2,6-dione), theobromine (3,7-dihydro-3,7-dimethyl-1H-purine-2,6-dione), and caffeine (3,7-dihydro-1,3,7-trimethyl-1H-purine-2,6-dione), are alkaloids that are widely distributed in plant products and beverages and are known to have many physiological effects, such as gastric acid secretion, diuresis, and stimulation of the central nervous system. They have also been implicated in various disorders including heart disease, carcinogenesis, kidney malfunction, and asthma $[1,2]$.

Table 1. Structure of xanthine and its naturally occurring N-methyl derivatives.

\begin{tabular}{|l|l|l|l|l|}
\hline Structure & $\mathrm{R}_{1}$ & $\mathrm{R}_{2}$ & $\mathrm{R}_{3}$ & Compound \\
\hline \multirow{2}{*}{$\mathrm{R}_{3}$} & $\mathrm{H}$ & $\mathrm{H}$ & $\mathrm{H}$ & Xanthine \\
\cline { 2 - 5 } \\
\cline { 3 - 5 }
\end{tabular}

Theophylline (3,7-dihydro-1,3-dimethyl-1H-purine-2,6-dione) as one of the xanthine-based alkaloids, has a stimulating effect on respiration and is widely used as a bronchodilator for the treatment of bronchial asthma and neonatal apnea [3-5]. Owing to the toxicity of theophylline and the variations in metabolism between individuals, the most accepted range of effective plasma theophylline concentrations in adults is between 5 and $20 \mu \mathrm{g} \mathrm{mL}^{-1}$ [5-7]. Levels below this range are usually non-therapeutic, while higher levels may cause serious toxicity. Excessive administration of theophylline occasionally produces serious toxicity, including vomiting, tachycardia, seizures and central nervous system excitation $[1,4,5]$.




The interest in monitoring the levels of TP in plasma has led to the development of a variety of methods, such as high performance liquid chromatography (HPLC) [8-11], electrokinetic capillary chromatography [1, 12], capillary electrophoresis [13], liquid chromatography [14], liquid chromatography-mass spectrometry [3], gas chromatography [11], spectrophotometry [7, $8,15]$ and differential-derivative spectroscopy [16]. Many of the above methods often require tedious extraction procedures employing organic solvents which pollute the environment and some requiring derivatization procedure before determination.

Electrochemical methods have been of great interest due to several advantages, including high sensitivity, comparative simplicity, rapid response and low cost [17]. Efforts have been made on the determination of theophylline using electrochemical methods and detection limits up to the order of $10^{-8} \mathrm{M}$ have been reported [4, 18-21]. However, the fabrication processes of most of the above listed electrodes are rather complicated and the surface renewing is not convenient.

Polymer-modified electrodes (PMEs) have received attention in recent years due to their good stability, reproducibility, increase in active sites, homogeneity in electrochemical deposition and strong adherence to electrode surface [22, 23].

Compared to metal electrodes, the glassy carbon electrode (GCE) has been widely used, due to its biocompatibility with tissue, low residual current over a wide potential range and minimal propensity to show deteriorated response as a result of electrode fouling [24]. In this paper, we used poly(AHNSA) modified GCE fabricated electrochemically from 4-amino-3hydroxynaphthalene sulfonic acid. The electrochemical behavior of TP in PBS at the polymermodified electrode was investigated. Hence, the purpose of this work is to develop an alternative; selective, sensitive, simple, environmentally friendly and easily fabricated modified electrode with wide linear range and low detection limit. Here we report an electrochemical method for the determination of TP at a poly(AHNSA)-modified glassy carbon electrode.

\section{EXPERIMENTAL}

\section{Apparatus and reagents}

4-Amino-3-hydroxynaphthalene sulfonic acid (AHNSA) was purchased from Sigma-Aldrich and theophylline anhydrous (TP) with purity of $99.70 \%$ was supplied by the China associate limited supplier. All buffer solutions (PBS) were prepared from $0.1 \mathrm{M}$ monopotassium orthophosphate or dipotassium orthophosphate solutions adjusted to the required $\mathrm{pH}$ with $0.1 \mathrm{M}$ $\mathrm{HCl}$ or $\mathrm{NaOH}$ using Jenway 3345 ion meter. All experiments were carried out at $20{ }^{0} \mathrm{C}$ temperature and all solutions were prepared from distilled water. The chemicals used were all of analytical grade (BDH, England) and were used without further purification.

BAS-50W electrochemical analyzer was used to perform all electrochemical measurements. A conventional three-electrode system comprising a bare GCE (3 $\mathrm{mm}$ in diameter) or poly(AHNSA) /GCE as a working electrode, saturated calomel electrode (SCE) as a reference electrode and platinum foil as auxiliary electrode was employed. All the potentials in this paper are given relative to $\mathrm{SCE}$.

\section{Procedure}

The glassy carbon electrode was mirror polished with $1.0,0.3$ and $0.05 \mu \mathrm{m}$ alumina powder, respectively. The residual polishing material was removed by repetitive rinsing of the surface with distilled water. Poly(4-amino-3-hydroxynaphthalene sulfonic acid), poly(AHNSA), was grown at the bare GC electrode potentiodynamically by scanning the potential between -0.8 and $+2.0 \mathrm{~V}$ at a scan rate of $100 \mathrm{mV} \mathrm{s}^{-1}$ for 15 cycles in a $2 \times 10^{-3} \mathrm{M}$ AHNSA/0.1 $\mathrm{M} \mathrm{HNO}_{3}$ solution. 
Then, the modified electrode was rinsed with distilled water and conditioned by sweeping it in $0.5 \mathrm{M} \mathrm{H}_{2} \mathrm{SO}_{4}$ between -0.8 and $+0.8 \mathrm{~V}$ at $100 \mathrm{mV} \mathrm{s}^{-1}$ until a stable voltammogram is obtained. Cyclic voltammetry $(\mathrm{CV})$ was used to study the electrochemical behavior of the polymer modified electrode.

A $25 \mathrm{mM}$ theophylline stock solution was prepared in distilled water and stored under refrigeration. Standard theophylline solutions of the desired concentrations were prepared from the stock solution by dilution using the appropriate $\mathrm{pH}$ PBS. CV was used to characterize the response of the modified electrode to TP. The effect of scan rate and buffer $\mathrm{pH}$ was also studied applying cyclic voltammetry.

Theophylline tablets (labelled as $120 \mathrm{mg}$ per tablet) were collected from two local pharmaceuticals manufacturing factories: Addis Pharmaceuticals Factory (APF) and Ethiopian Pharmaceuticals Factory (EPF). Stock solutions of the tablets from each factory were prepared by dissolving 3 randomly selected tablets in $500 \mathrm{~mL}$ of distilled water. 10 and $20 \mu \mathrm{M}$ TP tablet solutions were prepared from each stock solution by dilution with PBS ( $\mathrm{pH} 3.0)$. Triplicate measurements were made for each sample solution. The DPV results are summarized in Table 2. Furthermore, the recovery of the developed method was studied by comparing the experimental current response with the expected current for drug samples spiked with standard solutions. For this purpose, two solutions (A and B) were prepared from $10 \mathrm{~mL}$ of $10 \mu \mathrm{M}$ drug samples (EPF) spiked with $10 \mu \mathrm{M}$ and $20 \mu \mathrm{M}$ standard TP solutions, respectively. The results are summarized in Table 3.

\section{RESULTS AND DISCUSSION}

\section{Electropolymerization of AHNSA at the GCE surface}

$\mathrm{CV}$ was used to synthesize the polymer film. The potential scan range was the most important factor to prepare the poly(AHNSA) film on the glassy carbon electrode. No polymer formation takes place when the anodic potential is below $+2.0 \mathrm{~V}$ and the cathodic potential is above -0.8 V. Hence, the optimized potential window for the cyclic voltammetric electropolymerization of AHNSA at GCE was between -0.8 to +2.0 V. Figure 1 depicts the repetitive cyclic voltammograms of $2.0 \times 10^{-3} \mathrm{M}$ of AHNSA in $0.1 \mathrm{M} \mathrm{HNO}_{3}$ at a bare GCE between -0.8 and $+2.0 \mathrm{~V}$.

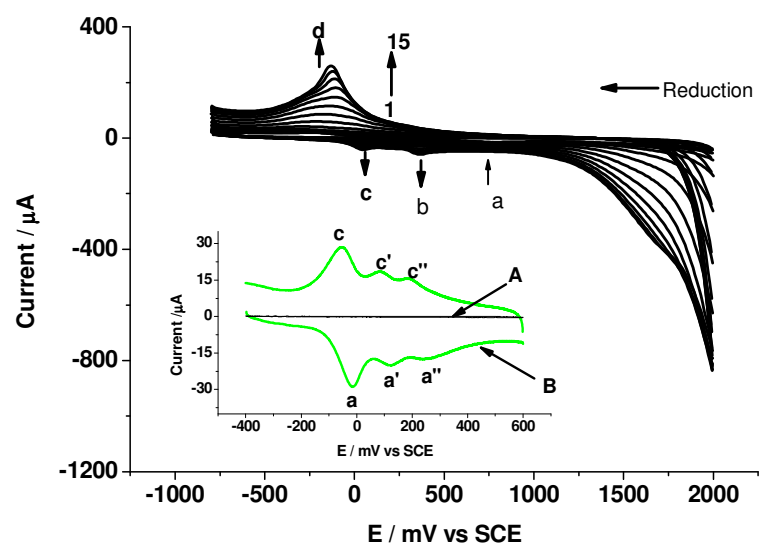

Figure 1. Repetitive CVs of $2.0 \times 10^{-3} \mathrm{M}$ AHNSA in $0.1 \mathrm{M} \mathrm{HNO}_{3}$ solution when the potential is scanned between -0.8 to $+2.0 \mathrm{~V}$ at a scan rate of $100 \mathrm{mV} \mathrm{s}^{-1}$ for 15 cycles. Inset: $\mathrm{CV}$ of bare GCE (curve A) and poly(AHNSA)/GCE (curve B) in a monomer free PBS (pH 5.0) at a scan rate of $100 \mathrm{mV} \mathrm{s}^{-1}$. 
In the first cycle, weak anodic peak $(b)$, strong anodic peak $(a)$ and cathodic peak $(d)$ were observed at about $+260,+720$ and $-300 \mathrm{mV}$, respectively. In the consecutive scans, anodic peak (c) appeared at about $+30 \mathrm{mV}$. Upon continuous scanning, the peak current growth of all except peak $(a)$ was accompanied by potential shift in a direction of anodic peaks to more positive and cathodic peaks to more negative directions. Unlike the other peaks, peak current of peak $(a)$ was observed to decrease with increasing scanning cycles indicating the presence of a species that is consumed with scan cycles.
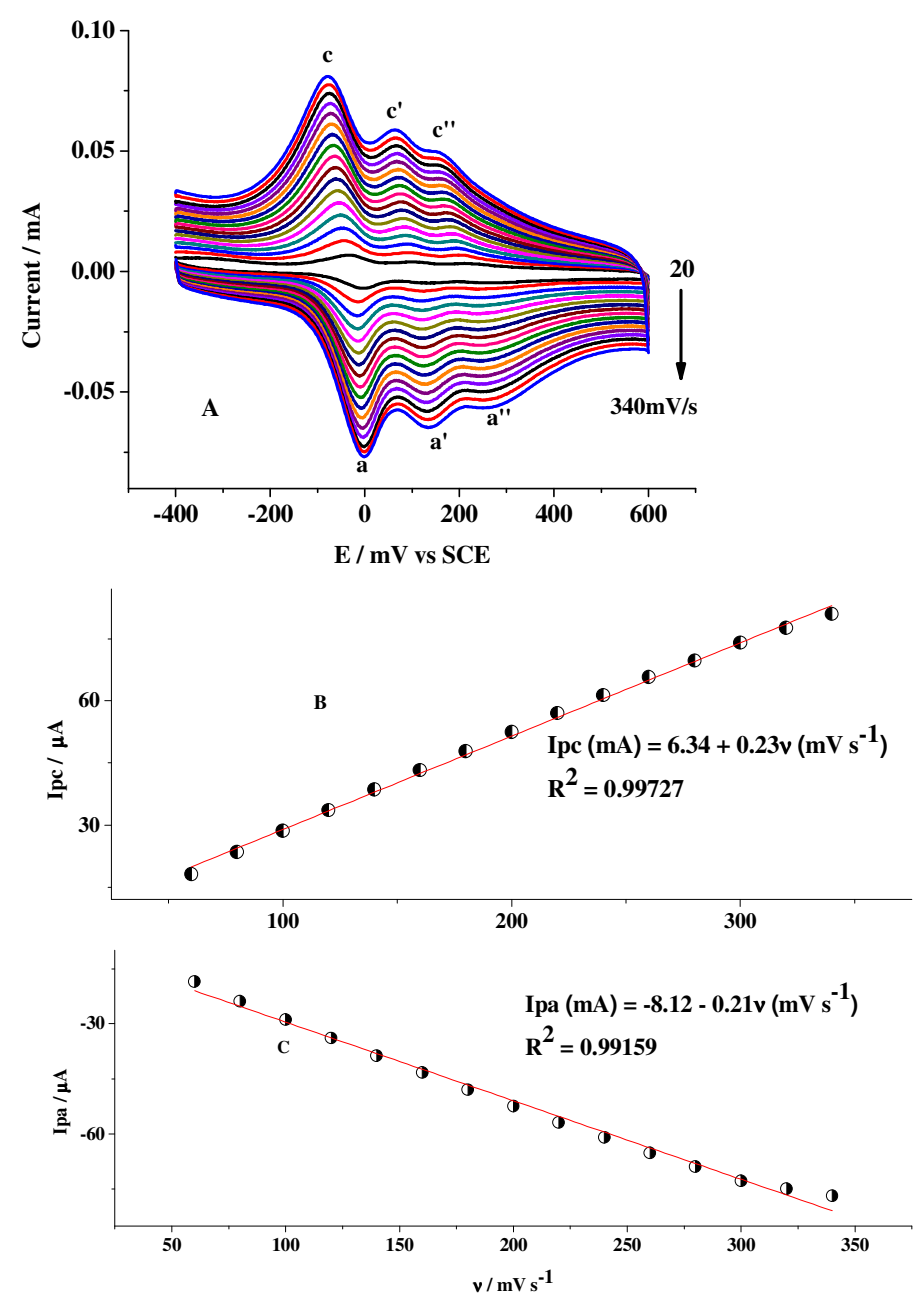

Figure 2. (A) CVs of poly(AHNSA)/GCE in PBS (pH 5.0), at scan rates of 20, 40, 60, 80, 100, $1200,140,160,180,200,220,240,260,280,300,320$ and $340 \mathrm{mV} \mathrm{s}^{-1}$. (B) Variation of $I_{p c}$ versus scan rates. (C) Variation of $I_{p a}$ versus scan rates.

Cyclic voltammetry was used to study the electrochemical behavior of poly(AHNSA) modified GCE. Inset of Figure 1 shows the cyclic voltammogram of unmodified GCE (A) and 
poly(AHNSA)/GCE (B) in a monomer free PBS ( $\mathrm{pH} 5.0$ ) at a scan rate of $0.1 \mathrm{~V} \mathrm{~s}^{-1}$. Contrasting the unmodified GCE, three couples of redox peaks designated as: a-c, a'-c', and a"-c" were observed at the modified electrode with peak-to-peak separations ( $\Delta_{E_{p}}=\left|E_{p c}-E_{p a}\right|$ ) of 39, 38 and $57 \mathrm{mV}$, respectively, which is characteristic of reversible redox couples governed by $\Delta E_{p}=(59 \mathrm{~m} / \mathrm{n}) \mathrm{mV}$; where $\mathrm{m}$ is number of protons and $\mathrm{n}$ number of electrons involved in the reaction. Thus, the results suggest that each redox couple in poly(AHNSA)/GCE shows reversible behavior with equal number of protons and electrons participated in an aqueous medium.

The effect of scan rate on the peak currents of the three redox couples was also investigated. Figure 3 depicts the cyclic voltammograms of poly(AHNSA)/GCE in a monomer free PBS (pH $5.0)$ at variable scan rates. The anodic and cathodic peak currents $\left(I_{p}\right)$ for the redox couple with the highest peak currents $(\mathrm{a}-\mathrm{c})$ increased linearly with increasing scan rate in the potential range 60 to $340 \mathrm{mV} \mathrm{s}^{-1}$ with a linear regression equation and correlation coefficient $\left(\mathrm{R}^{2}\right)$ of $I_{p a}(\mu \mathrm{A})=$ $-8.124-0.214 V\left(\mathrm{mV} \mathrm{s}^{-1}\right), I_{p c}=6.35+0.226 V\left(\mathrm{mV} \mathrm{s}^{-1}\right), 0.9916$ and 0.9973 , respectively (Figure 2B-C). Linear dependence of peak current on the scan rate is an indication of a redox process involving surface confined species [25] confirming the deposition of a polymer film at the electrode surface.

\section{Electrochemical behavior of TP on poly(AHNSA) modified electrode}

Figure 3 shows the cyclic voltammograms obtained for $1.0 \times 10^{-3} \mathrm{M} \mathrm{TP}$, in $0.1 \mathrm{M} \mathrm{PBS}(\mathrm{pH} 5.0$ ), at bare glassy carbon electrode (a) and poly(AHNSA) modified GCE (b). The electrochemical oxidation process revealed one broad and poor anodic peak centered at about $+1.37 \mathrm{~V}$ vs. SCE at the bare GCE. Under similar conditions, a sharp peak at $+1.22 \mathrm{~V}$ has been observed at the poly(AHNSA) modified GCE. The oxidation process of TP both at the bare and modified electrodes is irreversible. The potential shift towards negative direction accompanied by the remarkable peak current enhancement at the polymer-modified GCE are clear evidences of the catalytic effect of the poly(AHNSA) modified GCE towards TP oxidation. The catalytic effect of the polymer may be attributed partly to the increased effective surface area of the poly(AHNSA) modified GCE and partly to the $\mathrm{pH}$ dependent affinity of $\mathrm{TPH}^{+}$(protonated TP in acidic medium) for the negatively charged sulfonic group in the modifier structure.

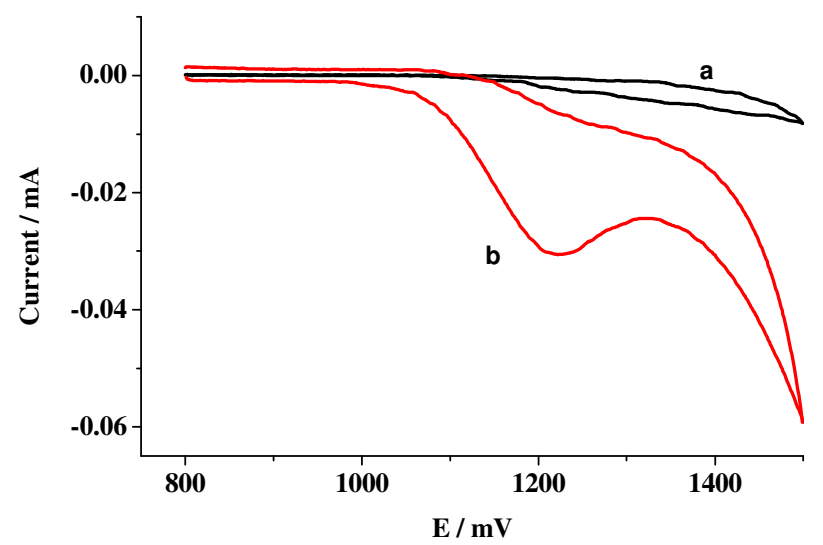

Figure 3. CVs of bare GCE (a) and poly(AHNSA) modified GCE (b) for $1.0 \times 10^{-3} \mathrm{M}$ TP in PBS (pH 5.0) at a scan rate of $100 \mathrm{mV} \mathrm{s}^{-1}$.

Bull. Chem. Soc. Ethiop. 2012, 26(1) 

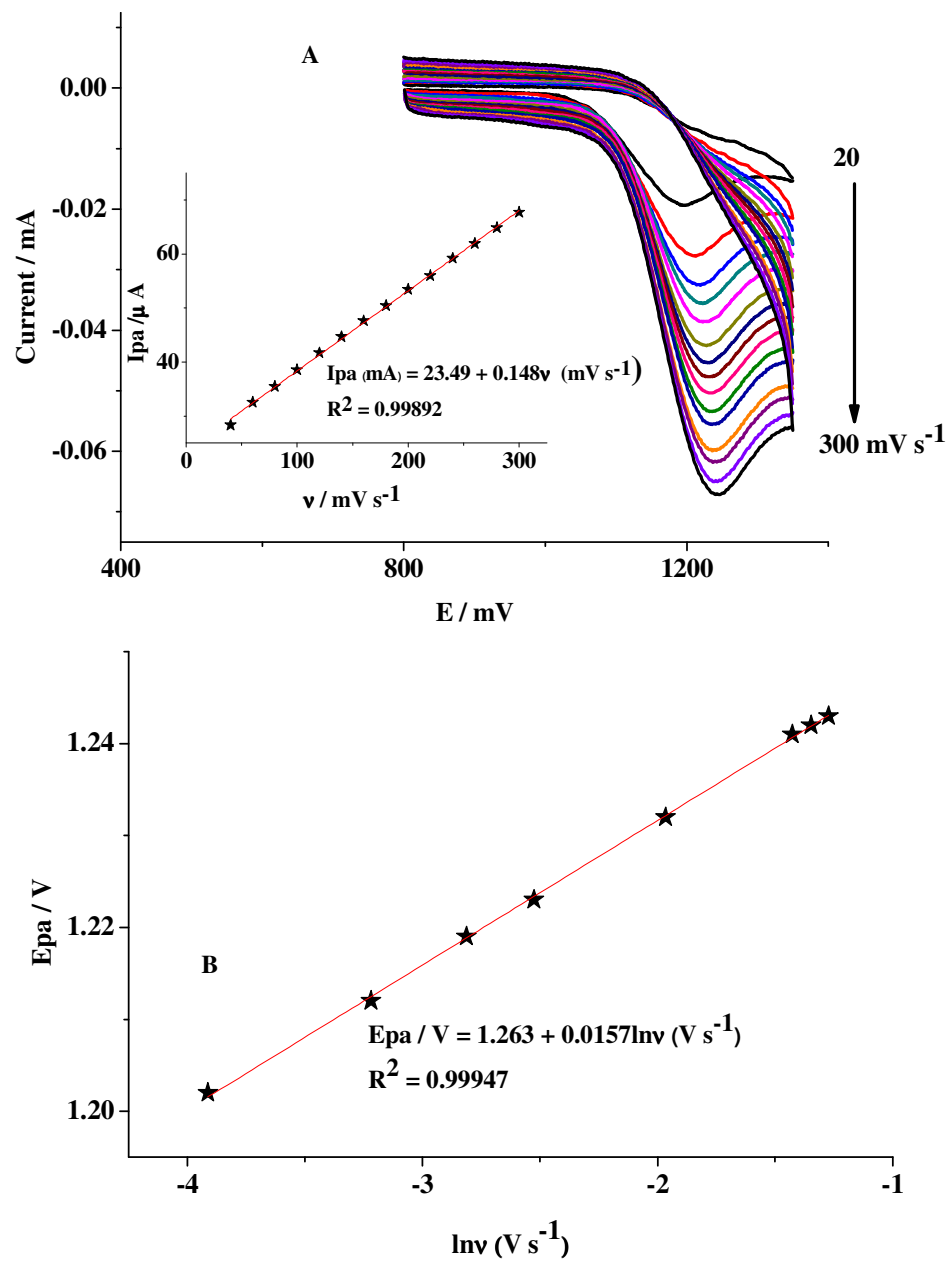

Figure 4. (A) CVs of the poly(AHNSA) modified GCE in PBS (pH 5.0) containing $1.0 \times 10^{-3} \mathrm{M}$ of TP, at scan rates of 20,40,60, 80, 100, 120, 140,160, 180, 200, 220, 240, 260, 280 , and $300 \mathrm{mV} \mathrm{s}^{-1}$. (Inset) corresponding linear dependence of peak current on the scan rate. (B) Linear curve for $E_{p a}$ versus the logarithm of scan rates.

The effect of scan rate on the oxidation peak potential $\left(E_{p a}\right)$ and, current $\left(I_{p a}\right)$ of TP at the poly(AHNSA) modified GCE was studied with cyclic voltammetry (CV). Figure 4A reveals the $\mathrm{CVs}$ of $1 \times 10^{-3} \mathrm{M}$ of TP in $\mathrm{pH} 5.0 \mathrm{PBS}$ at scan rates ranging between 20 and $300 \mathrm{mV} \mathrm{s}^{-1}$. The peak current $\left(I_{p a}\right)$ of TP showed linear dependence on the scan rate $(v)$ in the range 40 to 300 $\mathrm{mV} \mathrm{s}^{-1}$ (inset of Figure 4A) with a correlation coefficient of 0.99892 indicating an adsorptioncontrolled behavior during the electrode reaction [26]. The electrode reaction was irreversible as depicted from the lack of a reduction peak in the cyclic voltammograms (Figure 3). This was also further confirmed by the potential $\left(E_{p a}\right)$ shift to more positive values with increasing $v$ (Figure 4A). The relationship between $E_{p a}$ and $\ln v$ of an irreversible process obeys the following equation [4]: 
$E_{p a}=E^{0^{\prime}}+\frac{R T}{(1-\alpha) n F}\left\{0.780+\ln \left(\frac{D_{R}^{1 / 2}}{k^{0}}\right)+\ln \left[\frac{(1-\alpha) n F v}{R T}\right]^{1 / 2}\right\}$
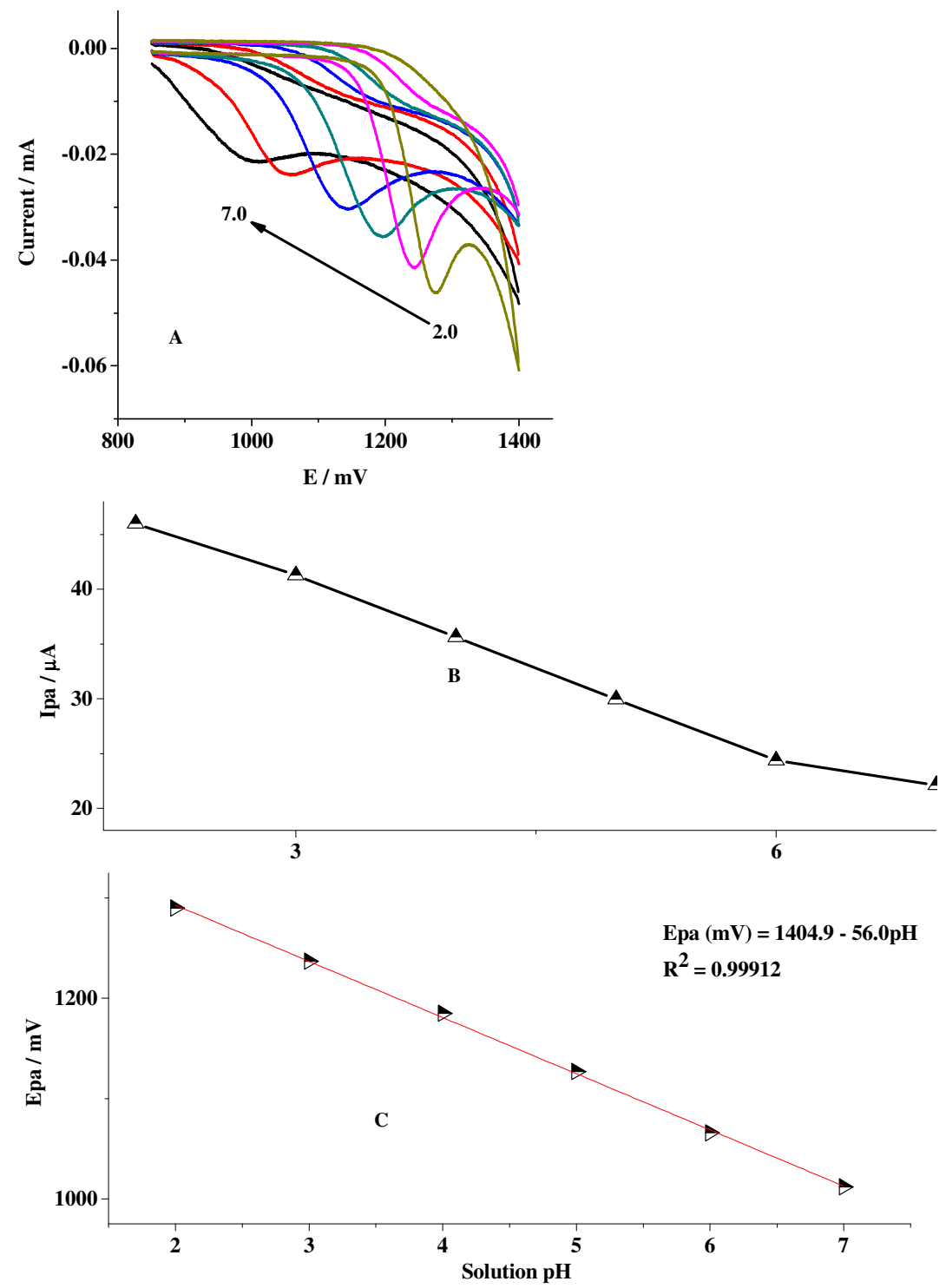

Figure 5. (A) CVs of $1.0 \times 10^{-3} \mathrm{M}$ TP at poly(AHNSA) modified GCE in different pHs (2.0 7.0) of PBS at a scan rate of $100 \mathrm{mV} \mathrm{s}^{-1}$. (B) Variation of $E_{p a}$ versus the $\mathrm{pH}$. (C) Plot of anodic peak current vs. various pHs. 
Based on the slope of the fitted line; $E_{p a}(\mathrm{~V})=1.263+0.0157 \ln \mathrm{v}$ and linear regression coefficient of 0.99947 ( Figure 4B), $\frac{R T}{2(1-\alpha) n F}=0.0157$, the value of $\mathrm{n}(1-\alpha)$ at the experimental temperature of $20{ }^{0} \mathrm{C}$ was calculated to be 0.804 . Taking the two electron oxidation of theophylline reported by Zhu et al. [4], the electron transfer coefficient, $\alpha$ was estimated to be 0.598 indicating the irreversibility of the system [27].

The effect of solution $\mathrm{pH}$ on peak potentials and peak currents of TP at the polymer modified electrode was also investigated. Cyclic voltammograms of $1.0 \times 10^{-3} \mathrm{M}$ TP in PBS of different $\mathrm{pHs}$ at poly(AHNSA) modified GCE are shown in Figure 5A. An increase in the pH of the solution caused oxidative peak potential shift in the negative direction. A linear correlation between the peak potential and solution $\mathrm{pH}$ was obtained (Figure 5B) with a linear equation and correlation coefficient of $E_{p a}\left(\mathrm{mV} \mathrm{s}^{-1}\right)=1404-56.0 \mathrm{pH}$ and $\mathrm{R}^{2}=0.99912$, respectively. A slope of $56.0 \mathrm{mV} / \mathrm{pH}$ suggests that the number of protons taking part in the electrode reaction is similar to the number of electrons. Hence, the oxidation of TP involves two electrons and two protons (Scheme 1) as suggested by Zhu et al. [4]:<smiles>CN1C(=O)N(C)N(C)C(=O)c2[nH]c([18OH])nc21</smiles>

Scheme 1. Mechanism for the oxidation of TP at poly(AHNSA)/GCE.

As can be seen from Figure 5C, the peak current response decreased with increasing $\mathrm{pH}$ values from 2.0 to 7.0 which is in agreement with the previous report [18]. The sharpness of the peaks also decreases along with increasing the $\mathrm{pH}$ of the solution. As seen in Figure 5C, it is at $\mathrm{pH} 2.0$ where maximum current is obtained. However, this voltammogram suffers from poor back ground current. The one at $\mathrm{pH} 3.0$ showed the next maximum current with lower back ground current effect and was taken as the preferred $\mathrm{pH}$ for further analysis. The decreasing trend of current response with increasing $\mathrm{pH}$ could partially be rationalized in terms of the possible interactions of the analyte and the polymer surface. The sulfonic functional group on the polymer film is negatively charged whose charge increases with increasing $\mathrm{pH}$. On the other hand, the theophylline is protonated as $\mathrm{TPH}^{+}$with $\mathrm{pK}_{\mathrm{a}}$ value of 8.8 [28] whose extent of charging decreases with increasing the solution $\mathrm{pH}$. Thus, the effective interaction between the two is the compromise between the charging of the theophylline and the polymer.

\section{Optimization of technique parameters}

Since DPV has a much higher current sensitivity and better resolution than cyclic voltammetry [29], the application of the poly(AHNSA) modified GCE for the quantitative analysis of TP has been investigated using DPV. Figure 6 shows that the polymer modified GCE (b) enhanced the current response by fifteen fold as compared to the bare GCE (a) in addition to shifting the potential towards less positive direction from 1370 to $1160 \mathrm{mV}$. These effects clearly show the catalytic roll of the polymer film. For further analysis, the DPV parameters such as the DPV scan rate and pulse amplitude have been optimized. 


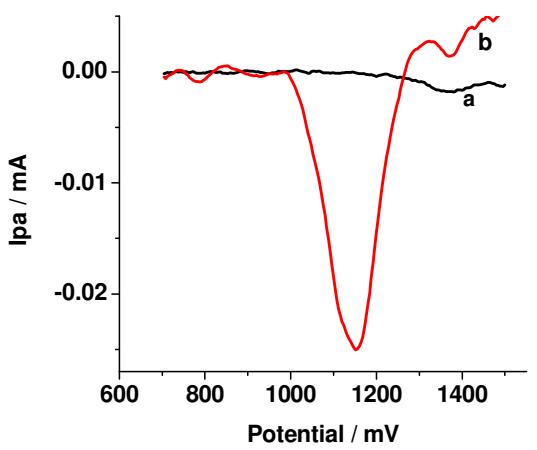

Figure 6. DPV of $1.0 \times 10^{-3} \mathrm{M}$ PT in PBS (pH 5.0) at (a) bare GCE and (b) poly(AHNSA) modified GCE.

The effects of DPV scan rate and DPV amplitude on the current response of poly(AHNSA)/GCE in $1 \times 10^{-3} \mathrm{MTP}$ (pH 5.0 PBS) were studied. The DPV scan rate and DPV pulse amplitude that give maximum peak current response were $60 \mathrm{mV} \mathrm{s}^{-1}$ and $100 \mathrm{mV}$, respectively.

The effects of accumulation potential $\left(E_{a c c}\right)$ and accumulation time $\left(t_{a c c}\right)$ on the current response of the modified electrode in $1 \times 10^{-3} \mathrm{M}$ TP (pH 5.0 PBS) were also investigated. Figure 7(A) shows the influence of the accumulation potential on the peak current. The current increases as the potential is varied in the positive direction and reaches maximum at a potential of $+50 \mathrm{mV}$ beyond which, the current response decreases. Thus, $+50 \mathrm{mV}$ was selected as the optimum preconcentration potential for accumulating TP on poly(AHNSA) modified GCE.

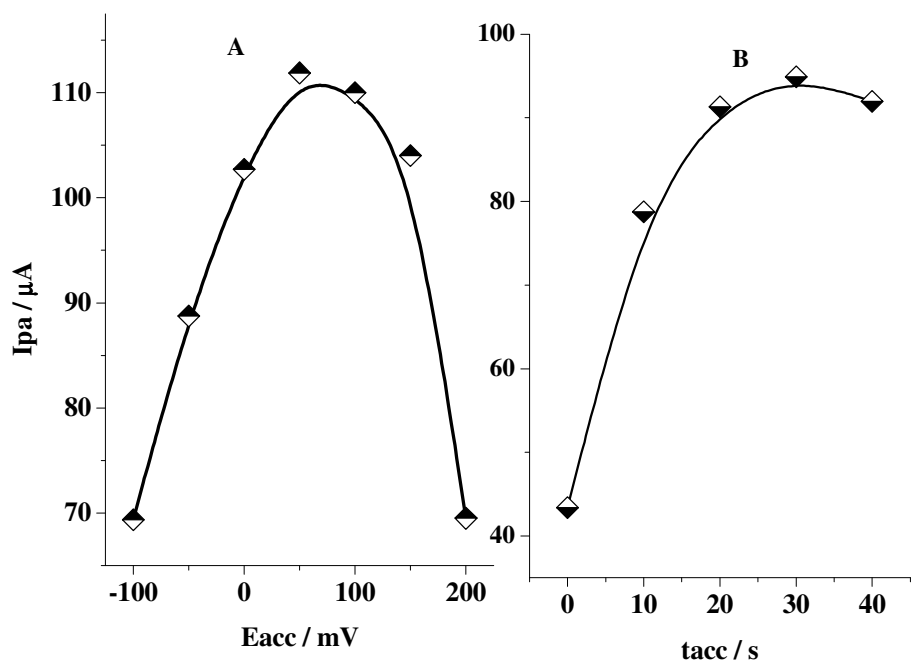

Figure 7. (A) Plot of the oxidative peak current of $1.0 \times 10^{-3} \mathrm{M}$ TP in PBS (pH 3.0) at poly(AHNSA)/GCE versus the preconcentration potential at a deposition time of $20 \mathrm{~s}$. (B) Plot of the oxidative peak current of $1.0 \times 10^{-3} \mathrm{M}$ TP in PBS (pH 3.0) at poly(AHNSA)/GCE versus the preconcentration time at a deposition potential of +50 $\mathrm{mV}$. 
Figure 7(B) demonstrates the effect of accumulation time on the peak current response. The peak current increases as the pre-concentration time increases up to $30 \mathrm{~s}$ and then begins to decline. Thus, $30 \mathrm{~s}$ was taken as the optimum pre-concentration time.

\section{Linear range and detection limit}

In order to see the feasibility of the explored method for the quantitative analysis of theophylline, the relationship between the oxidative peak current and the concentration of TP was studied using DPV. Under the optimized solution and method parameters, the DPVs of variable concentrations of TP are presented in Figure 8. The current response was linearly varied with concentration in the range $1.0 \times 10^{-6}-1.0 \times 10^{-4} \mathrm{M}$ with a linear regression equation, correlation coefficient and limit of detection $(3 \delta=\mathrm{S}$ for $\mathrm{n}=6)$ of $I_{p a}(\mu \mathrm{A})=0.03043+$ $1.8591 \mathrm{C}(\mu \mathrm{M}), 0.9983$ and $4.7 \times 10^{-8} \mathrm{M}$, respectively (inset of Figure 8).

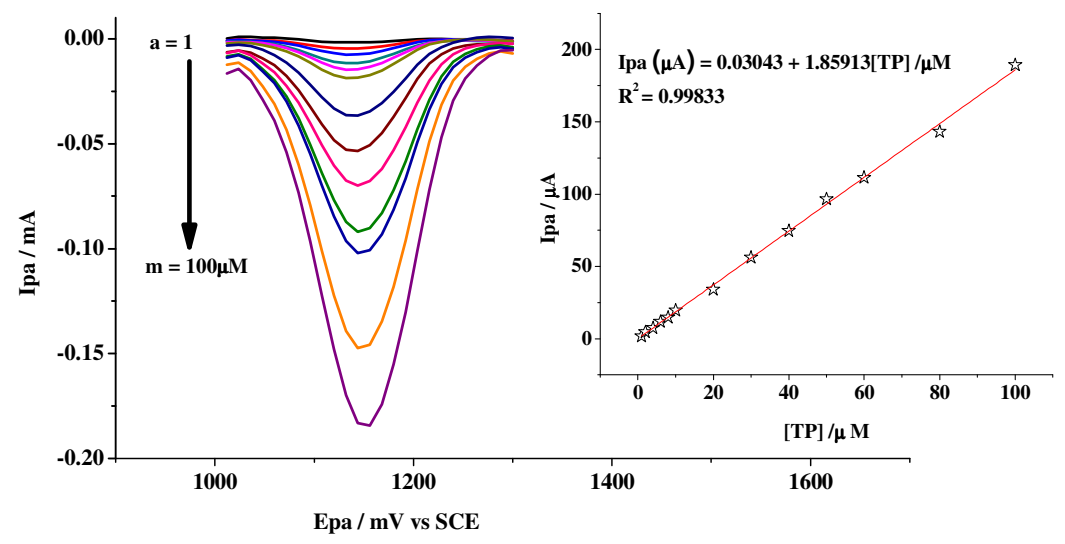

Figure 8. DPVs of poly(AHNSA) modified GCE in PBS ( $\mathrm{pH} 3.0$ ) for different concentrations of TP $(1,2,4,6,8,10,20,30,40,50,60,80$ and $100 \mu \mathrm{M})$ at the optimized parameters. (Inset) plot of peak currents $\left(I_{p a}\right)$ versus concentration of TP.

\section{Analytical application}

The applicability of the developed method for the determination of theophylline in real samples was investigated. The developed modified electrode was used for the determination of TP in tablet formulations collected from two local pharmaceuticals manufacturing factories: Addis Pharmaceuticals Factory (APF) and Ethiopian Pharmaceuticals Factory (EPF). The differential pulse voltammograms for 10 and $20 \mu \mathrm{M}$ samples from both factories were recorded and the results are summarized in Table 2. As can be seen from the Table, the results for the sample collected from the EPF are in good agreement with the marked content (120 mg per tablet).

Recovery experiments were also carried out to evaluate the matrix effect on the determination of TP at our electrode. The recoveries for 0.018 and $0.036 \mathrm{mg}$ standard TP from spiked theophylline drug samples are summarized in Table 3. Recoveries in the range 96.1$97.8 \%$ suggest that detection of theophylline using the developed modified electrode is not affected by ephedrine which is contained in the drug formulation and other sample matrix. These excellent recoveries suggest that the poly(AHNSA) modified GCE has a great potential for practical sample analysis. 
Table 2. Determination of TP in drug samples from two local pharmaceutical factories.

\begin{tabular}{|c|c|c|c|}
\hline Tablet sample & $\begin{array}{c}\text { TP added }[\mathrm{a}] \\
(\mu \mathrm{M})\end{array}$ & $\begin{array}{c}\text { TP found }[\mathrm{b}] \\
(\mu \mathrm{M})\end{array}$ & Recovery (\%) \\
\hline \multirow{2}{*}{$\mathrm{APF}$} & 10 & $6.29 \pm 0.059$ & 62.90 \\
\cline { 2 - 4 } & 20 & $15.56 \pm 0.265$ & 77.80 \\
\hline \multirow{2}{*}{ EPF } & 10 & $9.15 \pm 0.271$ & 91.49 \\
\cline { 2 - 4 } & 20 & $18.36 \pm 0.262$ & 91.78 \\
\hline
\end{tabular}

[a] Concentration as per the drug label (120 mg per tablet), [b] Mean of triplicate determinations.

Table 3. Recovery of TP from pharmaceutical (EPF) tablet solutions.

\begin{tabular}{|c|c|c|c|c|c|}
\hline $\begin{array}{c}\text { Sample } \\
\text { code }\end{array}$ & TP in drug sample (mg) & $\begin{array}{c}\text { Standard spiked } \\
(\mathrm{mg})\end{array}$ & $\begin{array}{c}\text { Found [a] } \\
(\mathrm{mg})\end{array}$ & $\begin{array}{c}\text { Recovery [b] } \\
(\%)\end{array}$ & RSD [c] (\%) \\
\hline A & 0.018 & 0.018 & 0.0356 & 97.78 & 3.2 \\
\hline B & 0.018 & 0.036 & 0.0526 & 96.11 & 1.4 \\
\hline
\end{tabular}

Mean of triplicate [a] measurements, [b] recoveries and [c] RSD of recoveries.

\section{Comparison with other methods}

Finally, the voltammetric determination of TP in this study is compared with other methods and is summarized in Table 4. It can be seen that the electrochemical sensor based on poly(AHNSA) modified GCE provides a comparable analytical performance but lower detection limit than most of the reported modified electrode. Furthermore, the poly(AHNSA) modified GCE offers easy modification with controlled film thickness and rapid electrode preparation compared to the other modified electrodes.

Table 4. Comparison between the newly developed and other similar reported techniques for the determination of TP.

\begin{tabular}{|l|c|c|c|c|}
\hline Electrode & Linear range (M) & Detection limit (M) & Method & Ref. \\
\hline MWNT/GCE & $3 \times 10^{-7}$ to $1 \times 10^{-5}$ & $5 \times 10^{-8}$ & CV & 4 \\
\hline Boron-doped diamond & 1 to $400 \times 10^{-6}$ & --- & LSV & 18 \\
\hline $\begin{array}{l}\text { Nafion®/lead-ruthenium oxide } \\
\text { pyrochlore/GCE }\end{array}$ & 0 to $100 \times 10^{-6}$ & $1 \times 10^{-7}$ & SWV & 20 \\
\hline Phthalocyanine Particles Modified CPE & $4.0 \times 10^{-7}$ to $1.0 \times 10^{-4}$ & $1.4 \times 10^{-7}$ & DPV & 21 \\
\hline Poly (AHNSA)/GCE & $1 \times 10^{-6}$ to $1 \times 10^{-4}$ & $4.7 \times 10^{-8}$ & DPV & This work \\
\hline
\end{tabular}

\section{CONCLUSIONS}

A novel poly(AHNSA) film modified GCE was fabricated by electropolymerization which showed three reversible redox couples in pH 5.0 PBS. The modified electrode showed good electrocatalytic activity for the irreversible oxidation of TP. The anodic peak current of TP was proportional to the concentration in the range $1.0 \times 10^{-6} \mathrm{M}$ to $100 \times 10^{-6} \mathrm{M}$, with a correlation coefficient, and detection limit $(\mathrm{S} / \mathrm{N}=3$ for $\mathrm{n}=6)$ of 0.9983 and $4.7 \times 10^{-8} \mathrm{M}$, respectively.

\section{REFERENCES}

1. Anbao, W.; Lijun, L.; Fang, Z.; Yuzhi, F. Anal. Chim. Acta 2000, 419, 235.

2. Turnball, A.J. Br. Nutr. Found-Nutr. Bull. 1981, 6, 153.

Bull. Chem. Soc. Ethiop. 2012, 26(1) 
3. Hideko, K.; Ryoko, A.; Yoshikazu, M.; Junko, K. J. Chromatogr. A 2000, 870, 87.

4. Yuan-Hai, Z.; Zhi-Ling, Z.; Dai-Wen, P. J. Electroanal. Chem. 2005, 581, 303.

5. Llobat-Estelles, M.J.; Marin-Saez, R.M.; San-Martin, M.D. Talanta 1996, 43, 1589.

6. Miroslav, S.; Andrea, P.; Stanislav, M.; Jozef, S. Anal. Biochem. 2000, 285, 225.

7. Susanto, F.; Humfeld, S.; Niederau, C.M.; Reinauer, H. Fresenius J. Anal. Chem. 1992, 344, 549.

8. Mohamed, H.A.; Mustafa, A.A.; Mohie, S. Analyst 1992, 117, 157.

9. Axel, M.; Tharcisse, N.; Günter, H. Fresenius J. Anal. Chem. 1996, 356, 284.

10. Kazoka, H. J. Chromatogr. A 1999, 836, 235.

11. Petr, S.; Alexandr, J.; Frantisek, D. J. Chromatogr. A 1994, 679, 195.

12. Quan-xun, D.; Ling-xiao, Y. J. Chromatogr. 1993, 630, 363.

13. Gang, C.; Qingcui, C.; Luyan, Z.; Jiannong, Y. Anal. Chim. Acta 2002, 457, 225.

14. Averrin, G.M.; Isiah, M.W. Anal. Chim. Acta 1995, 306, 49.

15. Hector, C.G.; Alejandro, C.O.; Arsenio, M.P. Anal. Chim. Acta 1999, 384, 95.

16. Nevin, E. J. Pharm. Biomed. Anal. 2000, 23, 255.

17. He, Z.; Jinsheng, Z.; Houting, L.; Huaisheng, W.; Renmin, L.; Jifeng, L. Int. J. Electrochem. Sci. 2010, 5, 295.

18. Nicolae, S.; Bulusu, V.S.; Donald, A.T.; Akira, F. Electroanalysis 2002, 14, 271.

19. Yogesh, K.; Om Prakash, M.; Mahipat, S.; Rajayashree, P. Int. J. ChemTech Res. 2010, 2, 1907.

20. Jyh-Myng, Z.; Tung-yue, Y.; Ying, S. Talanta 1999, 50, 635.

21. Gong-Jun, Y.; Kun, W.; Jing-Juan, X.; Hong-Yuan, C. Anal. Lett. 2005, 37, 629.

22. Ohnuki, Y.; Ohsaka, T.; Matsuda, H.; Oyama, N. J. Electroanal. Chem. 1983, 158, 55.

23. Volkov, A.; Tourillon, G.; Lacaze, P.C.; Dubois, J.E. J. Electroanal. Chem. 1980, 115, 279.

24. Van der Linden, W.E.; Dieker, J.W. Anal. Chim. Acta 1980, 119, 1.

25. Mohammad, M.; Hossein, R.; Hadi, B.; Bi Bi Fatemah, M.; Ali, A.; Nima, T. Int. J. Electrochem. Sci. 2010, 5, 147.

26. Xiao-Li, X.; Fei, H.; Guo-Liang, Z.; Song, Z.; Ji-Lie, K. Sensors 2010, 10, 8398.

27. Kangbing, W.; Junjie, F.; Shengshui, H. Anal. Biochem. 2003, 318, 100.

28. Ewa, K.; Borys, K.; David, S. Acta Biochim. Pol. 2004, 51, 493.

29. Mohammad, M.; Hadi, B.; Bahram, G.; Hossein, N.; Maryam, N. Bioelectrochemistry 2009, $75,1$. 